\title{
Resveratrol abrogates the effects of hypoxia on cell proliferation, invasion and EMT in osteosarcoma cells through downregulation of the HIF-1 $\alpha$ protein
}

\author{
YONGMING SUN, HAIBIN WANG, MING LIU, FANGUO LIN and JUN HUA \\ Department of Orthopaedics, The Second Affiliated Hospital of Soochow University, Suzhou, Jiangsu 215004, P.R. China
}

Received November 16, 2013; Accepted June 16, 2014

DOI: $10.3892 / \mathrm{mmr} .2014 .2913$

\begin{abstract}
Resveratrol has been shown to have antineoplastic effects in vivo and in vitro. However, the effect of resveratrol on the hypoxia-enhanced proliferation and invasion of osteosarcoma cells remains unclear. In this study, we investigated the role of resveratrol on regulating proliferation and invasion of osteosarcoma cells under hypoxic conditions. Saos-2 cells were cultured under controlled hypoxic conditions $\left(3 \% \mathrm{O}_{2}\right)$ or normoxic conditions. Resveratrol $(50 \mu \mathrm{M})$ was added in the medium, and hypoxia inducible factor- $1 \alpha$ (HIF-1 $\alpha)$ siRNA was used to inhibit $H I F-1 \alpha$ transcription. Proliferation of Saos-2 cells was evaluated by the methabenzthiazuron (MTT) assay. The invasive ability of Saos- 2 cells was determined by a Transwell assay. HIF-1 $\alpha$, E-cadherin and vimentin protein levels were detected by western blot analysis. $H I F-1 \alpha$, E-cadherin and vimentin mRNA levels were assessed by RT-PCR. Compared to the control group, hypoxia significantly increased the proliferation rate and invasive ability of Saos-2 cells. Moreover, hypoxia markedly increased the E-cadherin level and decreased vimentin expression. However, resveratrol or $H I F-1 \alpha$ silencing reverted all the above effects of hypoxia in Saos-2 cells. Moreover, resveratrol inhibited HIF-1 $\alpha$ protein accumulation without affecting the HIF-1 $\alpha$ mRNA level. These data suggest that resveratrol can inhibit the hypoxia-enhanced proliferation, invasion and epithelial to mesenchymal transition process in osteosarcoma via downregulation of the HIF-1 $\alpha$ protein. Thus, HIF-1 $\alpha$ may be a promising drug target of resveratrol in the context of development of anticancer therapy for human osteosarcoma.
\end{abstract}

\section{Introduction}

Osteosarcoma is the most common bone primary malignant tumor and mostly occurs in late childhood and early

Correspondence to: Professor Yongming Sun, Department of Orthopaedics, The Second Affiliated Hospital of Soochow University, 1055 Sanxiang Road, Suzhou, Jiangsu 215004, P.R. China E-mail: sun-ym@21cn.com

Key words: resveratrol, hypoxia inducible factor- $1 \alpha$, invasion, epithelial to mesenchymal transition, osteosarcoma adulthood (1). The application of adjuvant chemotherapy has increased the overall survival rate of osteosarcoma patients to more than $70 \%$ (2). However in patients with metastasis or recurrence, prognosis remains poor, with survival rates of only $20-30 \%(3,4)$. Without formal treatment, osteosarcoma cells tend to metastasize to new body sites, most commonly to the lung, within 6 months to 1 year, eventually leading to death (5). The mechanisms underlying progression and metastasis of this cancer type are only beginning to be elucidated, and novel, effective therapeutic agents are urgently needed.

Intratumoral hypoxia is a typical feature of solid tumors. It is mainly due to the abnormal formation of vasculature in the rapidly growing tumor mass. Tumor hypoxia has been correlated to increased tumor invasion, angiogenesis and distant metastasis (6-8). The adaptation of tumor cells to hypoxia has given rise to tumor heterogeneity and the selection of resistant clones, evolving into a more aggressive phenotype (9). The transcription factor hypoxia inducible factor- $1 \alpha$ (HIF-1 $\alpha$ ) mediates cellular responses to hypoxia. Overexpression of the HIF-1 $\alpha$ protein has been reported in numerous solid tumors and their metastases (9). Stabilization and activation of the $\mathrm{HIF}-1 \alpha / \mathrm{HIF}-1 \beta$ transcription complex is closely associated with cell proliferation, metastasis, angiogenesis, epithelial to mesenchymal transition (EMT), increased resistance to chemotherapy and radiotherapy, and tumor progression (10-15). Hence, it is likely that HIF-1 $\alpha$ may be used as an independent prognostic marker and as a predictor of the mortality risk and treatment failure in tumors (16-19).

Resveratrol (3,4',5-trihydroxystilbene) is a natural polyphenolic phytoalexin mainly found in plants, including grapes, peanuts, root extracts of the weed Polygonum cuspidatum, and various fruits (20). Resveratrol has been shown to have multiple bioactivities, including anti-oxidative, chemopreventive, antitumor, growth inhibitory, anti-inflammatory, estrogen-like, and immunoregulatory activity $(21,22)$. Resveratrol can affect various cellular events related to distinct steps of carcinogenesis, i.e., tumor initiation, promotion and progression $(23,24)$. Resveratrol has therapeutic potential due to its ability to suppress tumor cell growth via inducing cell-cycle arrest and apoptosis, and to suppress tumor angiogenesis via inhibiting the vascular endothelial growth factor (VEGF) protein (25-34). At the molecular level, these effects may be attributed to the inhibition of the formation of free radicals, and the inhibition of cyclooxygenase, cytochrome $\mathrm{P} 450$ and protein kinase C 
activities (35). Despite these findings however, the molecular mechanisms underlying the anticancer effects of resveratrol remain largely unknown $(6,25)$. Previous studies have shown for the first time that resveratrol exerts a strong inhibitory effect on HIF-1 $\alpha$ and VEGF expression in human ovarian cancer cells. These studies demonstrated that resveratrol interferes with the protein translational machinery and promotes HIF-1 $\alpha$ protein degradation, rather than affecting the $H I F-1 \alpha$ mRNA level $(6,22)$.

In this study, we focused on the regulation, by resveratrol, of cell proliferation, cell invasion and of the EMT process in the human osteosarcoma cell line Saos-2 under hypoxic conditions. We demonstrate that resveratrol markedly reduces the enhanced cell proliferation and migration in hypoxic conditions through downregulation of the HIF-1 $\alpha$ protein, and that it also inhibits the epithelial-mesenchymal transition.

\section{Materials and methods}

Materials. The human osteosarcoma cell line Saos-2 was purchased from the Shanghai Institutes for Biological Sciences (Chinese Academy of Sciences, Shanghai, China); McCOY's 5A, fetal bovine serum (FBS), trypsin, methabenzthiazuron (MTT), and dimethyl sulfoxide (DMSO) were purchased from Sigma-Aldrich (St. Louis, MO, USA); resveratrol was obtained from MP Biomedicals, Inc. (Aurora, $\mathrm{OH}$, USA). Antibodies were purchased from the following sources: anti-human anti-HIF-1 $\alpha$, -E-cadherin and -vimentin from Cell Signaling Technology (Boston, MA, USA); anti-human anti- $\beta$-actin, goat-anti-mouse and anti-rabbit IgG, and rabbit anti-goat IgG from Santa Cruz Biotechnology, Inc. (Santa Cruz, CA, USA). HIF-1 $\alpha$ small interfering (si)RNA and siRNA controls were obtained from Santa Cruz Biotechnology, Inc.; Transwell chambers from EMD Millipore (Billerica, MA, USA); Invitrogen ${ }^{\circledR}$ Lipofectamine 2000 from Thermo Fisher Scientific (Waltham, MA, USA); PCR mix from Xi'an Runde Biotechnology (Xi'an, China); and PCR primer sets from Dingguo Biotechnology Co., Ltd. (Beijing, China).

Cell cultures and transfection. The human osteosarcoma Saos-2 cell line was cultured in McCOY's 5A medium supplemented with $15 \% \mathrm{FBS}, 100 \mu \mathrm{g} / \mathrm{ml}$ ampicillin and $100 \mu \mathrm{g} / \mathrm{ml}$ streptomycin, at $37^{\circ} \mathrm{C}$ in a humidified atmosphere containing $5 \% \mathrm{CO}_{2}$. In experiments designed to evaluate the role of hypoxia, cells were first incubated in normoxic conditions to acquire the desired subconfluence level (65-70\%), and then cultured in controlled hypoxic conditions $\left(3 \% \mathrm{O}_{2}\right)$, as previously described $(36,37)$ for up to $24 \mathrm{~h}$. Osteosarcoma cells at the exponential phase were incubated in six orifice plates in McCOY's 5A supplemented with $1 \%$ FBS for $24 \mathrm{~h}$. The drugs (or solvent only) were then added to the medium containing $1 \%$ FBS, and cells were cultured for an additional $24 \mathrm{~h}$ prior to the Matrigel invasion assay.

Cell proliferation assay. Each group of cells was seeded onto a 96-well plate at a density of 5,000-10,000 cells/well for $24 \mathrm{~h}$ prior to serum starvation for $24 \mathrm{~h}$. Following starvation, cells were incubated in McCOY's 5A medium supplemented with $15 \%$ FBS. After 12, 24, 48 or $72 \mathrm{~h}$, the medium was removed, and the MTT reagent $(5 \mathrm{mg} / \mathrm{ml})$ was added in each well for a 4-h incubation at $37^{\circ} \mathrm{C}$. Optical densities (OD) were measured at $490 \mathrm{~nm}$ on a microplate reader (BioTek Instruments, Inc., Winooski, VA, USA). The proliferation rate was calculated as OD (sample)/OD (control). Reported values are the average of triplicate experiments.

Matrigel cell invasion assay. The invasive ability of each group of cells was evaluated though a Transwell chamber-based invasion assay. Briefly, the upper surface of the Transwell filter was coated with Matrigel (BD Biosciences, Franklin Lakes, NJ, USA). Before treatment, cells at the exponential phase were incubated in McCOY's 5A medium supplemented with $1 \%$ FBS for $24 \mathrm{~h}$ in 6 -well plates. The cells $\left(5 \times 10^{4}\right)$ were resuspended in serum-free medium and allowed to migrate towards a serum gradient $(20 \%)$ in the lower chamber for $24 \mathrm{~h}$, in a humidified tissue culture incubator. Non-invasive cells were removed from the top of the Matrigel by scraping with a cotton-tipped swab. Invasive cells at the bottom surface of the filter were fixed with $4 \%$ paraformaldehyde and stained with Crystal Violet dye (Boster Biological Technology, Ltd., Wuhan, China). The number of invasive cells was counted under a light microscope (Axio Observer A1; Carl Zeiss Microscopy GmbH, Jena Germany) at 10 random fields for each membrane, and pictures were acquired at x100 magnification with a AxiocaCam MRc5 camera (Carl Zeiss Microscopy GmbH). The tumor cell invasion assay was performed in triplicate.

Western blot assay. Saos-2 cells were washed with ice-cold phosphate-buffered saline and lysed in situ with RIPA buffer (50 mM Tris, $\mathrm{pH} 7.5,150 \mathrm{mM} \mathrm{NaCl}, 0.5 \%$ sodium deoxycholate, $1.0 \%$ Triton $\mathrm{X}-100,0.1 \%$ SDS), supplemented with protease inhibitors (Roche Diagnostics, Penzberg, Germany) and phosphatase inhibitors (Sigma-Aldrich). Following incubation on ice for $30 \mathrm{~min}$, cell lysates were centrifuged at $12,000 \mathrm{x} \mathrm{g}$ for $15 \mathrm{~min}$ at $4^{\circ} \mathrm{C}$ to remove the debris. Proteins $(100 \mu \mathrm{g})$ were separated by $10 \%$ SDS-PAGE and were transferred to polyvinylidene difluoride (PVDF) membranes (Roche Diagnostics). Then, the PVDF membranes were blocked with 5\% non-fat dry milk in TBST (10 mM Tris- $\mathrm{HCl}, \mathrm{pH} 8.0,150 \mathrm{mM} \mathrm{NaCl}$, $0.05 \%$ Tween-20) and incubated with the primary antibodies overnight at $4^{\circ} \mathrm{C}$. After washing with TBST five times for 10 min each, the PVDF membranes were incubated with horseradish peroxidase-conjugated secondary antibodies at room temperature for $2 \mathrm{~h}$. The membranes were washed again with TBST and an enhanced chemiluminescence (ECL) kit (USCN Life Science Inc., Wuhan, China) was used to visualize the immunoblots.

Reverse transcription-polymerase chain reaction (RT-PCR). Total RNAs were extracted from osteosarcoma cells with the Invitrogen ${ }^{\circledR}$ TRIzol reagent (Thermo Fisher Scientific) according to the manufacturer's protocol, and the RT reaction was performed using a PrimeScript RT Reagent kit (Takara, Dalian, China). cDNAs ( $1 \mu 1$ for each sample) were amplified by PCR using the following primer sequences: HIF-1 $\alpha$ forward (F), 5'-AAGTCTAGGGATGCAGCA-3', and reverse (R), 5'-CAAGATCACCAGCATCATG-3'; E-cadherin F, 5'-ATTCTGATTCTGCTGCTCTTG-3', and R, 5'-AGTCCT GGTCCTCTTCTCC-3'; vimentin F, 5'-AATGACCGCTTC GCCAAC-3', and R, 5'-CCGCATCTCCTCCTCGTAG-3'; 


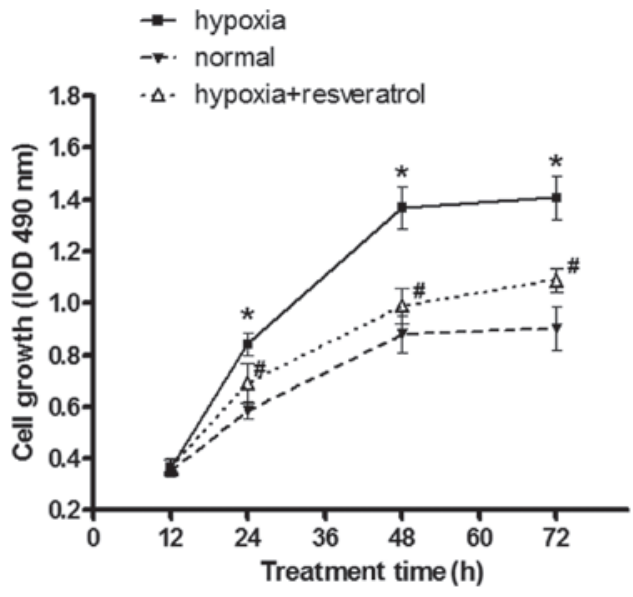

Figure 1. Effect of resveratrol on the hypoxia-enhanced proliferation rate of Saos- 2 cells. Saos-2 cells were incubated under normoxic or hypoxic conditions for $24 \mathrm{~h}$, then $50 \mu \mathrm{M}$ resveratrol as in $(22,25)$ were added to the medium, and cells were cultured for an additional $24 \mathrm{~h}$. Normal, hypoxia and hypoxia + resveratrol group cells were seeded in 96-well tissue culture plates at indicated time-points $(12,24,48$ or $72 \mathrm{~h}$ ), and the MTT assay was performed to determine the proliferation rate of the cells in each group Results compiled from three independent experiments are shown. ${ }^{*} \mathrm{P}<0.05$ as compared to the normal control (normoxia) group; ${ }^{\#} \mathrm{P}<0.05$ as compared to the hypoxia group; IOD, integrated optical density.

$\beta$-actin F, 5'-ATTCTGATTCTGCTGCTCTTG-3', and R, 5'-AGTCCTGGTCCTCTTCTCC-3'. $\beta$-actin was used as the normalization control. The amplified products were observed by $1.5 \%$ agarose gel electrophoresis. Images of the gel were acquired and analyzed under a UV transilluminator. The RT-PCR assay was carried out in triplicate.

RNA interference. siRNAs targeting the HIF-1a gene (HIF-1 $\alpha$-Homo-2258: 5'-CCACCACUGAUGAAUUAAATT-3' and 5'-UUUAAUUCAUCAGUGGUGGTT-3') and negative control siRNAs (NC: 5'-UUCUCCGAACGUGUCACGUTT-3' and 5'-ACGUGACACGUUCGGAGAATT-3') were purchased from Santa Cruz Biotechnology, Inc. Cells (10 $/$ well) seeded in 6-well plates were transfected with $100 \mathrm{nM}$ siRNA using the Lipofectamine 2000 reagent according to the manufacturer's instructions. The cells were used for further experiments at $48 \mathrm{~h}$ after transfection.

Statistical analysis. Data were expressed as the mean \pm standard deviation. Differences were evaluated using unpaired two-tailed Student's t-tests with unequal variance for multiple comparisons using the SPSS version 18.0 software (SPSS Inc., Chicago, IL, USA). P-values $<0.05$ were considered to indicate statistically significant differences. All experiments were independently repeated at least three times.

\section{Results}

Resveratrol attenuates the effect of hypoxia on increased proliferation of Saos-2 cells. To investigate the potential role of resveratrol on osteosarcoma Saos-2 cell proliferation under hypoxic conditions, normal (grown under normoxia) cells, hypoxic cells and hypoxic cells pre-treated with resveratrol were seeded onto 96-well plates at different time-points, and the proliferative rate of in each group was investigated by the
MTT assay. Hypoxia markedly increased the proliferation rate of Saos- 2 cells as compared to the normal cell group, and resveratrol significantly reduced the proliferation rate of the hypoxic cell group at different time-points (Fig. 1).

Resveratrol reverses the increased invasive ability of Saos-2 cells under hypoxia. We further tested the effect of resveratrol on the Saos-2 cell invasive ability under an hypoxic microenvironment. The results showed that hypoxia significantly increases the number of invasive Saos-2 cells as compared to normoxia, and resveratrol markedly reduced the invasive ability of hypoxic cells (Fig. 2).

Resveratrol inhibits the EMT process induced by hypoxia in Saos- 2 cells. To investigate whether Saos- 2 cells undergo EMT as a result of exposure to hypoxia, we examined the expression of markers of epithelial and mesenchymal phenotypes by western blot analysis. Hypoxic cells displayed decreased E-cadherin and increased vimentin expression (Fig. 3). However, when hypoxic cells were pre-treated with resveratrol, the hypoxia-induced EMT process was reversed. Resveratrol treatment caused a marked increase in the expression of E-cadherin, and a significant decrease in the expression of vimentin (Fig. 3).

Resveratrol attenuates the effects of hypoxia likely through downregulation of HIF-1 $\alpha$ in Saos-2 cells. We further investigated whether resveratrol inhibits HIF-1 $\alpha$ expression, which was induced in tumor cells upon exposure to hypoxic stress, a common condition in aggressive solid tumors. We observed that pretreatment of Saos-2 cells with resveratrol reduced the hypoxia-induced HIF-1 $\alpha$ protein accumulation without affecting the HIF-1 $\alpha$ mRNA level (Fig. 4). Quantitative data from the three repeated experiments, using $\beta$-actin as the normalized control, showed the relative HIF- $1 \alpha$ mRNA expression level ( \pm standard deviation) in each group was $0.136 \pm 0.042,0.758 \pm 0.084$ and $0.728 \pm 0.080$ for the normal, hypoxia and hypoxia + resveratrol groups, respectively. Furthermore, quantitative data from the three repeated experiments revealed the relative HIF-1 $\alpha$ protein expression levels ( \pm standard deviation), using $\beta$-actin as the normalization control, were $0.323 \pm 0.050,0.842 \pm 0.096$ and $0.419 \pm 0.046$ for the normal, hypoxia and hypoxia + resveratrol groups, respectively. These results indicate that the HIF-1 $\alpha$ protein level was signincantly decreased in the hypoxia + resveratrol group, when compared with the hypoxia group $(\mathrm{P}<0.05)$, however, no significant difference in HIF-1 $\alpha$ mRNA expression was identified $(\mathrm{P}>0.05)$.

Next, we investigated whether resveratrol attenuates the effects of hypoxia through downregulation of the $H I F-1 \alpha$ gene in Saos-2 cells. We transiently silenced HIF-la and analyzed its expression and cell growth under hypoxic conditions (Fig. 5A and B). In the si-control transfected group of cells exposed to hypoxic conditions, treatment with resveratrol significantly reduced the proliferation rate (Fig. 5C), increased the level of E-cadherin and decreased that of vimentin (Fig. 6A). Furthermore, resveratrol significantly decreased the invasive ability of Saos-2 cells, which was induced by hypoxia (Fig. 6B). In the si-HIF-1 $\alpha$-transfected group, however, resveratrol had no significant effect under hypoxic conditions (Figs. 5C and 6). 

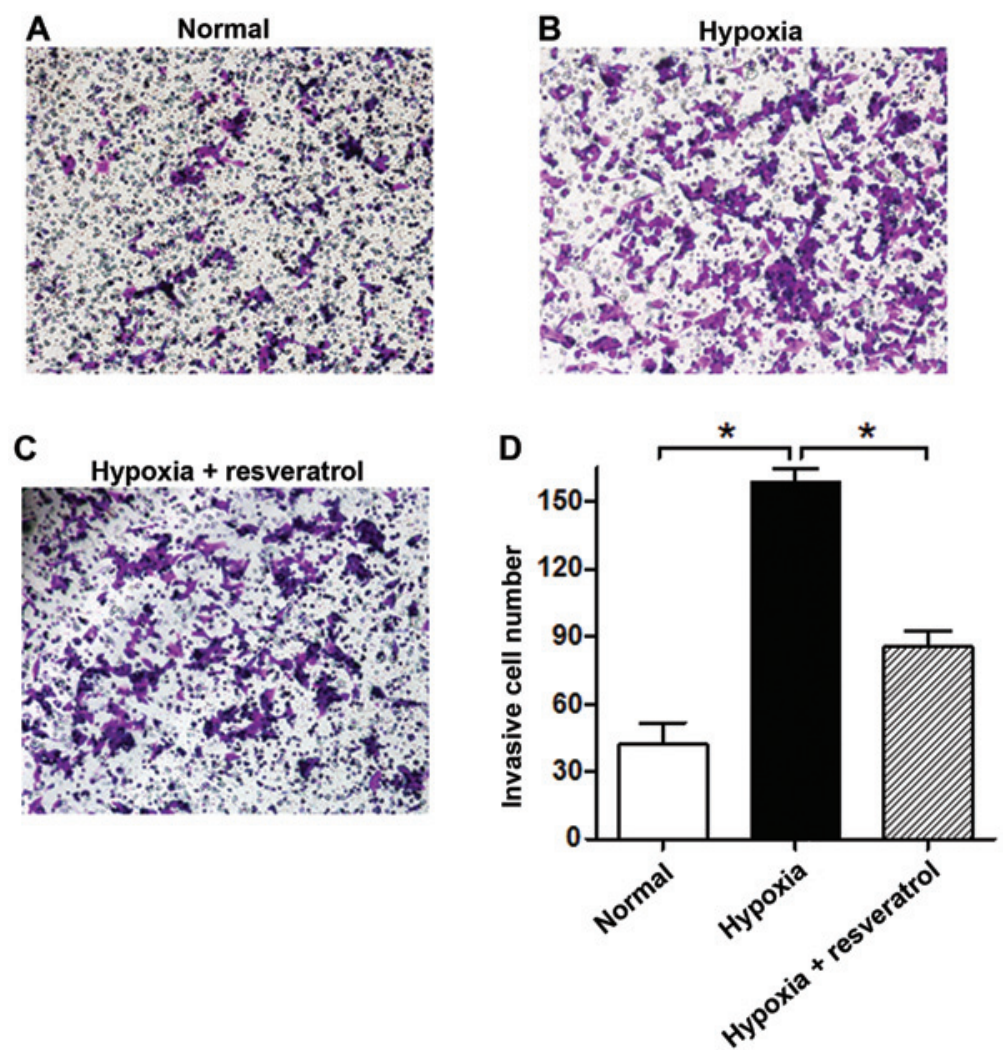

Figure 2. Effect of resveratrol on the invasive ability of Saos-2 cells under hypoxia. Saos-2 cells were incubated under normoxic or hypoxic conditions for $24 \mathrm{~h}$, then $50 \mu \mathrm{M}$ resveratrol was added to the medium, and cells were cultured for an additional $24 \mathrm{~h}$ prior to the Matrigel invasion assay. (A) Normal (normoxia) group, (B) hypoxia group, (C) hypoxia + resveratrol group, and (D) the number of invasive cells in each group, data compiled from three independent experiments. ${ }^{*} \mathrm{P}<0.05$. Bars, mean \pm standard deviation.
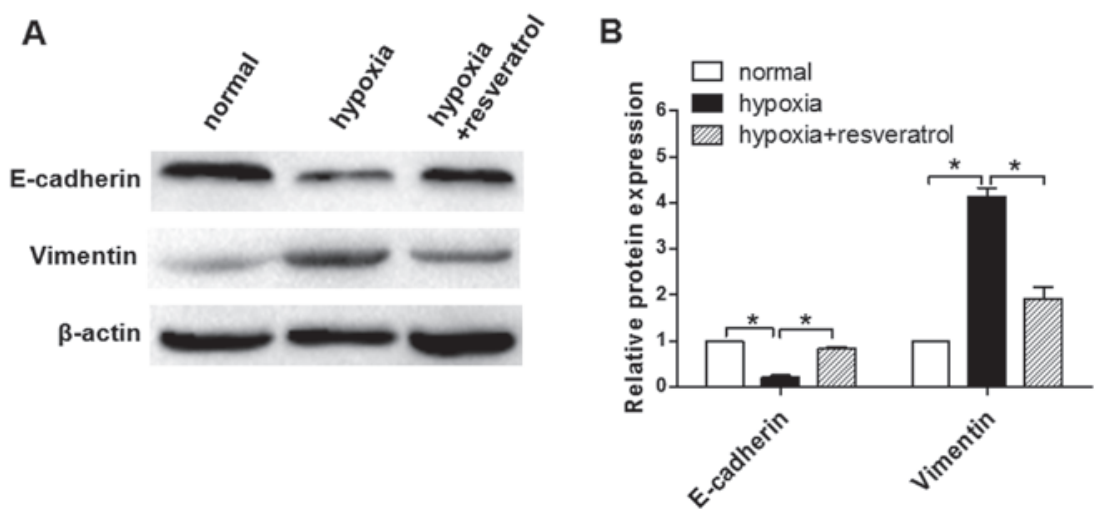

Figure 3. Effect of resveratrol on the epithelial to mesenchymal transition (EMT) process induced by hypoxia in Saos-2 cells. (A) The expression of EMT-related proteins (E-cadherin and vimentin) was evaluated by western blot analysis (representative blot from three independent experiments) following treatment of cells with $50 \mu \mathrm{M}$ resveratrol. (B) The integrated optical density was measured to assess the relative protein expression of EMT-related proteins, with $\beta$-actin used as the normalization control. Data compiled from of three independent experiments are shown. ${ }^{*} \mathrm{P}<0.05$. Bars, mean \pm standard deviation.

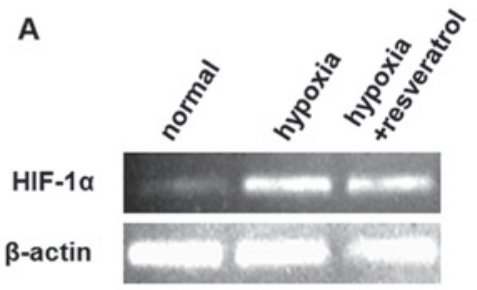

B

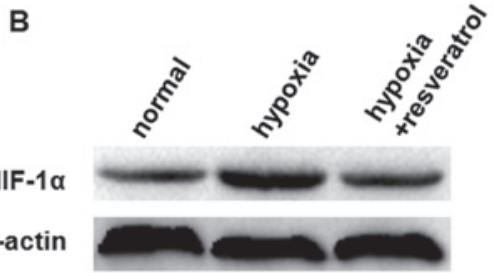

Figure 4. Effect of resveratrol on the hypoxia-induced accumulation of hypoxia inducible factor-1 $\alpha$ (HIF-1 $\alpha$ ) in Saos-2 cells. (A) After treatment with $50 \mu \mathrm{M}$ resveratrol for $24 \mathrm{~h}$, the mRNA level of HIF-1 $\alpha$ was estimated by reverse transcription-polymerase chain reaction. (B) The expression of the HIF-1 $\alpha$ protein was evaluated by western blot analysis. 
A

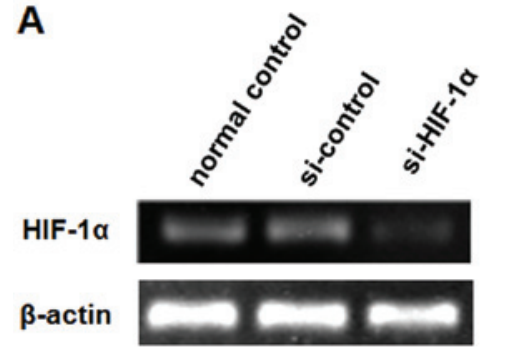

B

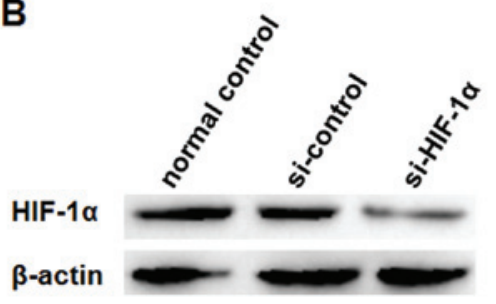

C

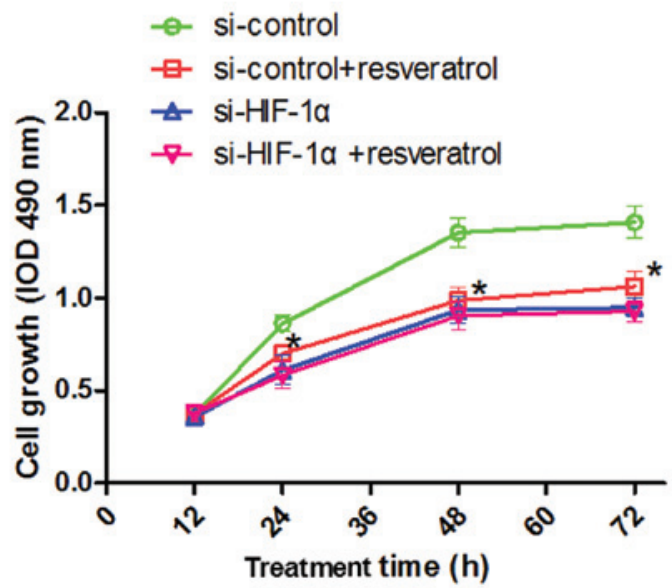

Figure 5. Effect of small interfering (si)RNA targeting the hypoxia inducible factor-1 $\alpha$ gene $(H I F-1 \alpha)$ on proliferation of Saos-2 cells under hypoxic conditions, $48 \mathrm{~h}$ after transfection. Detection, in siRNA-transfected Saos-2 cells (si-HIF-1 $\alpha$ ) of the HIF-1 $\alpha$ (A) mRNA by reverse transcription-polymerase chain reaction and (B) protein by western blot analysis. (C) The effect of $H I F-1 \alpha$ silencing on cell proliferation, assessed by the methabenzthiazuron (MTT) assay."P $<0.05$ compared with the normal group .

A

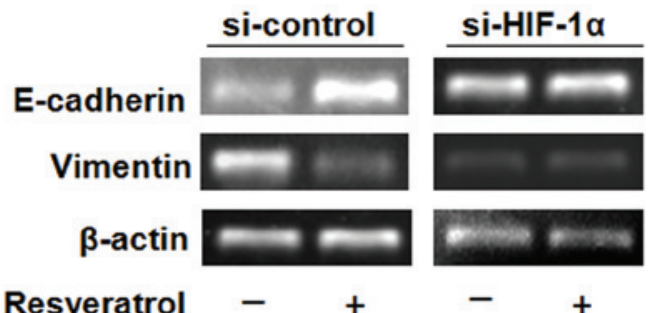

B

Resveratrol
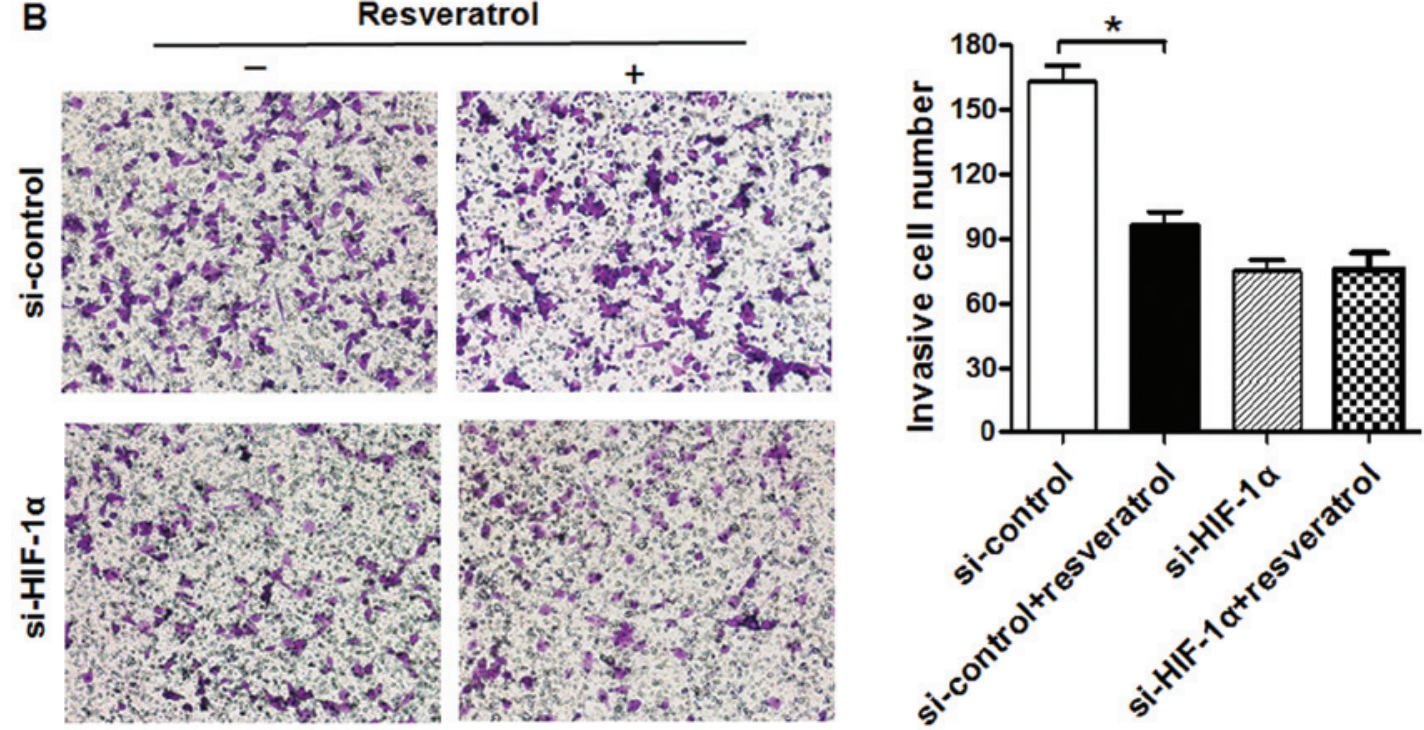

Figure 6. Effect of hypoxia inducible factor-1 $\alpha(H I F-1 \alpha)$ silencing on hypoxia-induced invasiveness and protein expression in Saos-2 cells. Following transfection with siRNA for $48 \mathrm{~h}$, Saos-2 cells were cultured with or without $50 \mu \mathrm{M}$ of resveratrol under hypoxic conditions. (A) The effects of $H I F-1 \alpha$ silencing on the epithelial to mesenchymal transition (EMT) process of Saos-2 cells. The expression of the EMT-related genes E-cadherin and vimentin was evaluated by reverse transcription-polymerase chain reaction. (B) The effects of $H I F-1 \alpha$ silencing on the invasive ability of Saos-2 cells, estimated by the Matrigel invasion assay. The number of cells was counted under a light microscope. ${ }^{*} \mathrm{P}<0.05$. Bars, mean \pm standard deviation $(\mathrm{n}=10)$.

These findings suggest that HIF-1 $\alpha$ expression plays a vital role in the resveratrol-abrogated effects of hypoxia in Saos-2 cells.

\section{Discussion}

Invasive solid tumors often present a characteristic hypoxic 
microenvironment, which leads to an abnormality in the microvasculature and a rapid expansion of the tumor mass. Previous studies have demonstrated that the effects induced by hypoxia is mainly mediated by HIF-1 $\alpha$ (9). HIF-1 $\alpha$ overexpression was observed in numerous solid tumors including glioma, pancreatic cancer and prostate carcinoma cells, as well as human tongue squamous cell carcinomas (9,38-41). Previous studies have shown that HIF-1 $\alpha$ overexpression, either as a result of intratumoral hypoxia or genetic alterations, increases the transcription of downstream genes, which contributes to cancer cell invasion (41-43). These findings indicate that there is an association between hypoxia or HIF-1 $\alpha$ overexpression and tumor invasion or patient mortality (43). In the present study, we showed that resveratrol markedly inhibits the promoting effect of hypoxia on the invasive ability of Saos-2 cells.

The epithelial to mesenchymal transition (EMT) is considered a dynamic and reversible biological process. It has now became apparent that EMT plays important roles in the progression of cancer (44). Hypoxia is associated with the EMT process, and HIF-1 $\alpha$ was shown to mediate the hypoxiainduced changes in the EMT (42). Recently, resveratrol was reported to have antitumor activities, including the ability to inhibit the EMT process in tumors. A number of studies have shown that resveratrol can suppress the EMT process through reactivating $\mathrm{p} 53$ and by inducing miR-145 and miR$200 \mathrm{c}$, suppressing the PI3K/Akt/nuclear factor- $\kappa \mathrm{B}(\mathrm{NF}-\kappa \mathrm{B})$ pathway, downregulating the PI3K/Akt and Wnt/ $\beta$-catenin signaling cascades, or inhibiting transforming growth factor- $\beta 1$ (TGF- $\beta 1$ ) in vitro. In addition, resveratrol treatment reduced the levels of EMT markers in xenograft tumors in vivo (45-50). In our experiments, resveratrol reversed the hypoxia-enhanced EMT process by affecting the expression of related proteins.

Several in vitro studies have demonstrated that resveratrol can inhibit the proliferation of a number of tumor types, such as leukemia, prostate, breast and colon cancers, as well as osteosarcoma, under normoxic conditions $(23,51-53)$. The results from the present study provide evidence that resveratrol also has an inhibitory effect on hypoxia-enhanced proliferation of osteosarcoma (Saos-2) cells.

Resveratrol exerts a strong inhibitory effect on HIF-1 $\alpha$ expression in certain human cancer cells $(8,22)$. These studies showed that resveratrol interferes with the protein translational machinery and promotes HIF- $1 \alpha$ protein degradation rather than affecting the $H I F-1 \alpha$ mRNA levels. In the present study, we showed that resveratrol markedly inhibits HIF-1 $\alpha$ protein expression without affecting the $H I F-1 \alpha$ mRNA level. Silencing of $H I F-1 \alpha$ reversed all the above-mentioned effects of hypoxia, which indicates that the effect of resveratrol on hypoxia may be attributed to its inhibitory effects on HIF-1 $\alpha$ protein expression. However, additional studies are needed to identify the associated genes that are directly or indirectly involved in resveratrol-regulated cancer cell invasion in response to hypoxia and/or HIF-1 $\alpha$ overexpression.

\section{Acknowledgements}

We thank all laboratory technicians in the Translational Medicine Research Center of Suzhou University School for their guidance in molecular biology techniques.

\section{References}

1. Stiller CA: International patterns of cancer incidence in adolescents. Cancer Treat Rev 33: 631-645, 2007.

2. Link MP, Goorin AM, Miser AW, et al: The effect of adjuvant chemotherapy on relapse-free survival in patients with osteosarcoma of the extremity. N Engl J Med 314: 1600-1606, 1986.

3. Harting MT, Blakely ML, Jaffe N, et al: Long-term survival after aggressive resection of pulmonary metastases among children and adolescents with osteosarcoma. J Pediatr Surg 41: 194-199, 2006.

4. Meyers PA, Heller G, Healey JH, et al: Osteogenic sarcoma with clinically detectable metastasis at initial presentation. J Clin Oncol 11: 449-453, 1993.

5. Geller DS and Gorlick R: Osteosarcoma: a review of diagnosis, management, and treatment strategies. Clin Adv Hematol Oncol 8: 705-718, 2010.

6. Michieli P: Hypoxia, angiogenesis and cancer therapy: to breathe or not to breathe? Cell Cycle 8: 3291-3296, 2009.

7. Pennacchietti S, Michieli P, Galluzzo M, Mazzone M, Giordano S and Comoglio PM: Hypoxia promotes invasive growth by transcriptional activation of the met protooncogene. Cancer Cell 3: 347-361, 2003

8. Esteban MA, Tran MG, Harten SK, et al: Regulation of E-cadherin expression by VHL and hypoxia-inducible factor. Cancer Res 66: 3567-3575, 2006.

9. Semenza GL: Targeting HIF-1 for cancer therapy. Nat Rev Cancer 3: 721-732, 2003.

10. Cheng ZX, Sun B, Wang SJ, et al: Nuclear factor- $\kappa \mathrm{B}-d e p e n d e n t$ epithelial to mesenchymal transition induced by HIF-1 $\alpha$ activation in pancreatic cancer cells under hypoxic conditions. PLoS One 6: e23752, 2011.

11. Semenza GL: HIF-1 and tumor progression: pathophysiology and therapeutics. Trends Mol Med 8: S62-S67, 2002.

12. Imai T, Horiuchi A, Wang C, et al: Hypoxia attenuates the expression of E-cadherin via up-regulation of SNAIL in ovarian carcinoma cells. Am J Pathol 163: 1437-1447, 2003.

13. Yang $\mathrm{MH}$ and $\mathrm{Wu} \mathrm{KJ}$ : TWIST activation by hypoxia inducible factor-1 (HIF-1): implications in metastasis and development. Cell Cycle 7: 2090-2096, 2008.

14. Harris AL: Hypoxia - a key regulatory factor in tumour growth. Nat Rev Cancer 2: 38-47, 2002.

15. Gupta GP and Massague J: Cancer metastasis: building a framework. Cell 127: 679-695, 2006.

16. Birner P, Schindl M, Obermair A, Plank C, Breitenecker G and Oberhuber G: Overexpression of hypoxia-inducible factor 1alpha is a marker for an unfavorable prognosis in early-stage invasive cervical cancer. Cancer Res 60: 4693-4696, 2000.

17. Birner P, Schindl M, Obermair A, Breitenecker G and Oberhuber G: Expression of hypoxia-inducible factor 1alpha in epithelial ovarian tumors: its impact on prognosis and on response to chemotherapy. Clin Cancer Res 7: 1661-1668, 2001.

18. Aebersold DM, Burri P, Beer KT, et al: Expression of hypoxia-inducible factor-1alpha: a novel predictive and prognostic parameter in the radiotherapy of oropharyngeal cancer. Cancer Res 61: 2911-2916, 2001.

19. Koukourakis MI, Giatromanolaki A, Skarlatos J, et al: Hypoxia inducible factor (HIF-1 $\alpha$ and HIF-2 $\alpha$ ) expression in early esophageal cancer and response to photodynamic therapy and radiotherapy. Cancer Res 61: 1830-1832, 2001.

20. Soleas GJ, Diamandis EP and Goldberg DM: Wine as a biological fluid: history, production, and role in disease prevention. J Clin Lab Anal 11: 287-313, 1997.

21. Aggarwal BB, Bhardwaj A, Aggarwal RS, Seeram NP, Shishodia S and Takada Y: Role of resveratrol in prevention and therapy of cancer: preclinical and clinical studies. Anticancer Res 24: 2783-2840, 2004.

22. Zhang Q, Tang X, Lu QY,Zhang ZF, Brown J and Le AD: Resveratrol inhibits hypoxia-induced accumulation of hypoxia-inducible factor-1alpha and VEGF expression in human tongue squamous cell carcinoma and hepatoma cells. Mol Cancer Ther 4: 1465$1474,2005$.

23. Jang M, Cai L, Udeani GO, et al: Cancer chemopreventive activity of resveratrol, a natural product derived from grapes. Science 275: 218-220, 1997.

24. Kundu JK, Chun KS, Kim SO and Surh YJ: Resveratrol inhibits phorbol ester-induced cyclooxygenase-2 expression in mouse skin: MAPKs and AP-1 as potential molecular targets. Biofactors 21: 33-39, 2004. 
25. Cao Z, Fang J, Xia C, Shi X and Jiang BH: trans-3,4,5'-Trihydroxystibene inhibits hypoxia-inducible factor lalpha and vascular endothelial growth factor expression in human ovarian cancer cells. Clin Cancer Res 10: 5253-5263, 2004.

26. Aziz MH, Kumar R and Ahmad N: Cancer chemoprevention by resveratrol: In vitro and in vivo studies and the underlying mechanisms (review). Int J Oncol 23: 17-28, 2003.

27. Jiang H, Zhang L, Kuo J, et al: Resveratrol-induced apoptotic death in human U251 glioma cells. Mol Cancer Ther 4: 554-561, 2005.

28. Wang TT, Schoene NW, Kim EK and Kim YS: Pleiotropic effects of the sirtuin inhibitor sirtinol involves concentration-dependent modulation of multiple nuclear receptor-mediated pathways in androgen-responsive prostate cancer cell LNCaP. Mol Carcinog 52: 676-685, 2013

29. Juan ME, Alfaras I and Planas JM: Colorectal cancer chemoprevention by trans-resveratrol. Pharmacol Res 65: 584-591, 2012.

30. Liu P, Wang X, Hu C and Hu T: Inhibition of proliferation and induction of apoptosis by trimethoxyl stilbene (TMS) in a lung cancer cell line. Asian Pac J Cancer Prev 12: 2263-2269, 2011.

31. Zhou JH, Cheng HY, Yu ZQ, He DW, Pan Z and Yang DT: Resveratrol induces apoptosis in pancreatic cancer cells. Chin Med J (Engl) 124: 1695-1699, 2011.

32. Yu HB, Zhang HF, Zhang X, et al: Resveratrol inhibits VEGF expression of human hepatocellular carcinoma cells through a NF-kappa B-mediated mechanism. Hepatogastroenterology 57: 1241-1246, 2010

33. Li Y, Bäckesjö CM, Haldosén LA and Lindgren U: Resveratrol inhibits proliferation and promotes apoptosis of osteosarcoma cells. Eur J Pharmacol 609: 13-18, 2009.

34. Liu Z, Li Y and Yang R: Effects of resveratrol on vascular endothelial growth factor expression in osteosarcoma cells and cell proliferation. Oncol Lett 4: 837-839, 2012.

35. Gusman J, Malonne $\mathrm{H}$ and Atassi G: A reappraisal of the potential chemopreventive and chemotherapeutic properties of resveratrol Carcinogenesis 22: 1111-1117, 2001

36. Aleffi S, Petrai I, Bertolani C, et al: Upregulation of proinflammatory and proangiogenic cytokines by leptin in human hepatic stellate cells. Hepatology 42: 1339-1348, 2005.

37. Novo E, Cannito S, Zamara E, et al: Proangiogenic cytokines as hypoxia-dependent factors stimulating migration of human hepatic stellate cells. Am J Pathol 170: 1942-1953, 2007.

38. Zagzag D, Zhong H, Scalzitti JM, Laughner E, Simons JW and Semenza GL: Expression of hypoxia-inducible factor 1alpha in brain tumors: association with angiogenesis, invasion, and progression. Cancer 88: 2606-2618, 2000.

39. Zhong H, Chiles K,FeldserD, et al: Modulation of hypoxia-inducible factor lalpha expression by the epidermal growth factor/phosphatidylinositol 3-kinase/PTEN/AKT/FRAP pathway in human prostate cancer cells: implications for tumor angiogenesis and therapeutics. Cancer Res 60: 1541-1545, 2000.

40. Zhang Q, Zhang ZF, Rao JY, et al: Treatment with siRNA and antisense oligonucleotides targeted to HIF-lalpha induced apoptosis in human tongue squamous cell carcinomas. Int J Cancer 111: 849-857, 2004
41. Akakura N, Kobayashi M, Horiuchi I, et al: Constitutive expression of hypoxia-inducible factor-1alpha renders pancreatic cancer cells resistant to apoptosis induced by hypoxia and nutrient deprivation. Cancer Res 61: 6548-6554, 2001.

42. Lei J, Ma J, Ma Q, et al: Hedgehog signaling regulates hypoxia induced epithelial to mesenchymal transition and invasion in pancreatic cancer cells via a ligand-independent manner. Mol Cancer 12: 66, 2013.

43. Krishnamachary B, Berg-Dixon S, Kelly B, et al: Regulation of colon carcinoma cell invasion by hypoxia-inducible factor 1 . Cancer Res 63: 1138-1143, 2003.

44. Huber MA, Kraut N and Beug H: Molecular requirements for epithelial-mesenchymal transition during tumor progression. Curr Opin Cell Biol 17: 548-558, 2005.

45. Shi XP, Miao S, Wu Y, et al: Resveratrol sensitizes tamoxifen in antiestrogen-resistant breast cancer cells with epithelialmesenchymal transition features. Int J Mol Sci 14: 15655-15668, 2013.

46. Shen YA, Lin $\mathrm{CH}$, Chi WH, et al: Resveratrol impedes the stemness, epithelial-mesenchymal transition, and metabolic reprogramming of cancer stem cells in nasopharyngeal carcinoma through p53 activation. Evid Based Complement Alternat Med 2013: 590393, 2013.

47. Li W, Ma J, Ma Q, et al: Resveratrol inhibits the epithelialmesenchymal transition of pancreatic cancer cells via suppression of the PI-3K/Akt/NF- $\kappa \mathrm{B}$ pathway. Curr Med Chem 20: 4185-4194, 2013

48. Tsai JH, Hsu LS, Lin CL, et al: 3,5,4'-Trimethoxystilbene, a natural methoxylated analog of resveratrol, inhibits breast cancer cell invasiveness by downregulation of PI3K/Akt and Wnt $/ \beta$-catenin signaling cascades and reversal of epithelialmesenchymal transition. Toxicol Appl Pharmacol 272: 746-756, 2013

49. Wang $\mathrm{H}$, Zhang $\mathrm{H}$, Tang L, et al: Resveratrol inhibits TGF- $\beta 1$-induced epithelial-to-mesenchymal transition and suppresses lung cancer invasion and metastasis. Toxicology 303: 139-146, 2013.

50. Hu FW, Tsai LL, Yu CH, Chen PN, Chou MY and Yu CC: Impairment of tumor-initiating stem-like property and reversal of epithelial-mesenchymal transdifferentiation in head and neck cancer by resveratrol treatment. Mol Nutr Food Res 56: 1247-1258, 2012.

51. Mitchell SH, Zhu W and Young CY: Resveratrol inhibits the expression and function of the androgen receptor in $\mathrm{LNCaP}$ prostate cancer cells. Cancer Res 59: 5892-5895, 1999.

52. Schneider Y, Vincent F, Duranton B, et al: Anti-proliferative effect of resveratrol, a natural component of grapes and wine, on human colonic cancer cells. Cancer Lett 158: 85-91, 2000.

53. Estrov Z, Shishodia S, Faderl S, et al: Resveratrol blocks interleukin-1beta-induced activation of the nuclear transcription factor NF-kappaB, inhibits proliferation, causes S-phase arrest, and induces apoptosis of acute myeloid leukemia cells. Blood 102: 987-995, 2003. 